\title{
Relationship Between Lipid Profile and Sepsis Outcome in Intensive
}

\section{Care Unit}

\author{
Mohammad Delirrad (iD ${ }^{1}$, Naser Gharebaghi (iD) ${ }^{2}$, Saina Mobarhan (iD) ${ }^{3}$ and Rahim Nejadrahim (iD) ${ }^{2, *}$ \\ ${ }^{1}$ Department of Medical Toxicology, Faculty of Medicine, Urmia University of Medical Sciences, Urmia, Iran \\ ${ }^{2}$ Department of Infectious Diseases, Faculty of Medicine, Urmia University of Medical Sciences, Urmia, Iran \\ ${ }^{3}$ Faculty of Medicine, Urmia University of Medical Sciences, Urmia, Iran \\ "Corresponding author: Department of Infectious Diseases, Faculty of Medicine, Urmia University of Medical Sciences, Urmia, Iran. Email: nejadrahim.r@umsu.ac.ir
}

Received 2019 May 13; Revised 2020 March 04; Accepted 2020 March 12.

\begin{abstract}
Background: Sepsis is the leading cause of death in critically ill patients in Intensive Care Units (ICUs). Lipid metabolism may change during sepsis.

Objectives: This study aimed to evaluate the lipid profile in patients with sepsis.

Methods: After approval of the local ethics committee, all adult patients admitted to a medical ICU of a tertiary teaching hospital were enrolled for one year in a prospective cross-sectional study. The inclusion criterion was the primary diagnosis of sepsis based on the probable or proved source of infection or positive blood culture. The exclusion criterion was the use of any lipid-reducing medications. The serum levels of triglyceride (TG), cholesterol, low-density lipoprotein (LDL), and high-density lipoprotein (HDL) were measured for each patient on the first day after ICU admission. Patients were divided into survivors and non-survivors. Quantitative variables were reported as the mean $( \pm S D)$. The independent samples $t$-test was used to compare the means between the two groups.

Results: Of 112 patients, 24 were excluded due to the use of lipid-reducing medications. Of 88 enrolled patients, $54.5 \%$ were male. The average age was $71.49 \pm 11.06$ years, and the in-hospital fatality rate was $63.6 \%$. The mean level of TG was significantly higher in survivors than in non-survivors ( $111.16 \pm 37.83$ vs. $100.75 \pm 21.42 \mathrm{mg} / \mathrm{dL}, \mathrm{t}=1.429, \mathrm{P}=0.002)$. Cholesterol, $\mathrm{LDL}$, and HDL levels did not show statistically significant differences between the two groups.

Conclusions: Our study illustrated that a lower TG level is associated with higher mortality in patients with sepsis in the ICU. Triglyceride may be used as a clinical indicator to assess the outcome of patients with sepsis.
\end{abstract}

Keywords: Sepsis, Triglycerides, Cholesterol, Lipid, Mortality, Prognosis, Clinical Outcome

\section{Background}

Sepsis is a life-threatening disease worldwide with increasing incidence over the past four decades (1). Despite extensive research and improved standards of care, sepsis has remained a disorder with a high mortality rate. In the United States, sepsis develops in 970,000 people annually, more than 210,000 of whom die, and these numbers have been continuously rising(2). Sepsis is the leading cause of death in critically ill patients admitted to Intensive Care Units (ICUs) and accounts for more than $50 \%$ of in-hospital fatalities $(3,4)$. Sepsis mortality increases dramatically with greater disease severity: $10 \%-20 \%$ for sepsis, $20 \%-40 \%$ for severe sepsis, and $40 \%-80 \%$ for septic shock (2)

Sepsis is accompanied by severe metabolic alterations. Thus, efforts have started and continued for many years to find some prognostic indicators among these alterations. Different biomarkers have been used for the diagnosis of sepsis, with no sufficient prognostic value. Several scoring systems such as Sequential Organ Failure assessment (SOFA) (5-8), quick SOFA (7, 9), Acute Physiology and Chronic Health evaluation (APACHE) (10-12), Simplified Acute Physiology score (SAPS) (12), and various laboratory parameters such as inflammatory cytokines (e.g., tumor necrosis factor, interleukins, C-reactive protein) (13, 14), procalcitonin (14-16), bilirubin (17), plasma lipids and lipoproteins (13, 17-23), etc., have been evaluated as prognostic factors of sepsis.

On the other hand, treatment with statins in clinical trials has led to a decrease in the severity of the disease, inflammation, and mortality of septic patients (24-28). It is believed that lower plasma levels of lipids in septic patients may decrease the ability for detoxifying endotoxins 
and deteriorate the patients' conditions with effects on immunomodulation (29). However, data on serum lipid alterations in sepsis are inconclusive.

\section{Objectives}

Therefore, the current study aimed to investigate the lipid profile changes in patients with sepsis in a medical ICU.

\section{Methods}

In a prospective cross-sectional survey, we studied all adult patients who were consecutively admitted to a medical ICU of a tertiary teaching hospital for one Iranian year (21 Mar 2017 to 20 Mar 2018). The inclusion criterion was a diagnosis of sepsis by an infectious disease specialist, according to the Third International Consensus Definitions of Sepsis and Septic Shock in 2016, which defines sepsis as a life-threatening organ dysfunction caused by a dysregulated host response to infection (30). The exclusion criterion was the use of any lipid-reducing medication, including statins. The demographic characteristics of patients (age, sex) and baseline serum lipid profile [triglyceride (TG), cholesterol, low-density lipoprotein (LDL), and high-density lipoprotein (HDL)] measured in the first $24 \mathrm{~h}$ of admission, were recorded in a checklist for each patient. Based on mortality in the hospital, the patients were divided into two groups: survivors and non-survivors. Quantitative variables were reported as the mean $( \pm S D)$. The independent samples $t$-test was used to compare the mean of variables between the two groups. All P values were twosided, and $\mathrm{P}<0.05$ was considered significant for all tests. The study was conducted following the Helsinki Declaration, and it was approved by the Ethics Committee of the Deputy of Research and Technology, Urmia University of Medical Sciences, Urmia, Iran. All statistical analyses were carried out using SPSS for Windows version 16 software (SPSS Inc., Chicago, IL, USA).

\section{Results}

Overall, 112 patients were admitted to the ICU with a diagnosis of sepsis during the one-year study period from whom 24 patients were excluded due to the use of lipid-reducing medications. Finally, 88 patients were enrolled. After diagnostic and therapeutic care, 32 patients were eventually improved and discharged from the hospital (survival group), and 56 patients died in the hospital (non-survival group). The patients' characteristics are summarized in Table 1. Also, Table 2 shows the lipid profiles of the two groups. The level of TG was significantly higher in non-survivors than in survivors. Cholesterol, HDL, and LDL levels did not show statistically significant differences between the two groups.

\begin{tabular}{|c|c|c|c|}
\hline & \multicolumn{2}{|c|}{ Outcome } & \multirow{2}{*}{ Total } \\
\hline & Non-Survival & Survival & \\
\hline \multicolumn{4}{|l|}{ Mean age } \\
\hline $\begin{array}{l}\text { Mean } \pm S D \\
y\end{array}$ & $73.70 \pm 10.43$ & $67.62 \pm 11.24$ & $71.49 \pm 11.06$ \\
\hline Range, y & $(49-93)$ & $(45-87)$ & $(45-93)$ \\
\hline \multicolumn{4}{|l|}{ Gender } \\
\hline \multicolumn{4}{|l|}{ Male } \\
\hline Count & 32 & 16 & 48 \\
\hline $\begin{array}{l}\text { Within } \\
\text { gender, \% }\end{array}$ & 66.7 & 33.3 & 100.0 \\
\hline $\begin{array}{l}\text { Within } \\
\text { outcome, } \\
\%\end{array}$ & 57.1 & 50.0 & 54.5 \\
\hline \multicolumn{4}{|l|}{ Female } \\
\hline Count & 24 & 16 & 40 \\
\hline $\begin{array}{l}\text { Within } \\
\text { gender, \% }\end{array}$ & 60.0 & 40.0 & 100.0 \\
\hline $\begin{array}{l}\text { Within } \\
\text { outcome, } \\
\%\end{array}$ & 42.9 & 50.0 & 45.5 \\
\hline \multicolumn{4}{|l|}{ Total } \\
\hline Count & 56 & 32 & 88 \\
\hline $\begin{array}{l}\text { Within } \\
\text { gender, \% }\end{array}$ & 63.6 & 36.4 & 100.0 \\
\hline $\begin{array}{l}\text { Within } \\
\text { outcome, \% }\end{array}$ & 100.0 & 100.0 & 100.0 \\
\hline
\end{tabular}

\section{Discussion}

It is necessary to investigate the biomarkers with diagnostic and prognostic value in sepsis (18). In this study, we evaluated the lipid profiles of 88 adult patients with sepsis in a medical ICU at a tertiary teaching hospital. The mean age of the studied patients was 71.5 years, with a mortality rate of $63.6 \%$. A recent study of the epidemiology and costs of sepsis in the United States reported the mean age of 65 years and overall mortality of $12.5 \%$, which varied by severity $(5.6 \%, 14.9 \%$, and $34.2 \%$ for sepsis without organ dysfunction, severe sepsis, and septic shock, respectively] (2).

Luthold et al. (31) studied the lipid profiles of 101 critically ill adult patients who were consecutively admitted to a medical ICU in a university medical center in Basel, Switzerland. The median age was 59 (range: 23 - 86) years, 


\begin{tabular}{|c|c|c|c|c|c|c|}
\hline \multirow{2}{*}{ Indicator } & \multirow{2}{*}{ Reference Value } & \multicolumn{2}{|c|}{ Outcome } & \multirow{2}{*}{ Total } & \multirow{2}{*}{$\mathbf{t}$} & \multirow{2}{*}{ P Value } \\
\hline & & Non-Survival & Survival & & & \\
\hline $\mathrm{TG}, \mathrm{mg} / \mathrm{dL}$ & $\begin{array}{c}\text { Up to } 150=\text { normal; } \\
150-200= \\
\text { borderline; }>200= \\
\text { abnormal }\end{array}$ & $\begin{array}{c}100.75 \pm 21.42(67- \\
156)\end{array}$ & $\begin{array}{c}111.16 \pm 37.83(51- \\
215)\end{array}$ & $\begin{array}{c}107.38 \pm 33.07(51- \\
215)\end{array}$ & 1.429 & 0.002 \\
\hline $\begin{array}{l}\text { Cholesterol, } \\
\text { mg/dL }\end{array}$ & $\begin{array}{l}\text { Up to } 200=\text { normal; } \\
200-240= \\
\text { borderline; }>240= \\
\text { abnormal }\end{array}$ & $\begin{array}{c}139.00 \pm 20.90(98- \\
181)\end{array}$ & $\begin{array}{c}140.89 \pm 26.92(97- \\
213)\end{array}$ & $\begin{array}{c}140.20 \pm 24.79(97- \\
213)\end{array}$ & 0.343 & 0.112 \\
\hline LDL, mg/dL & $\begin{array}{c}<130=\text { normal } ; 130 \\
160=\text { borderline; }> \\
160=\text { abnormal }\end{array}$ & $\begin{array}{c}79.28 \pm 18.53(50- \\
118)\end{array}$ & $\begin{array}{c}77.37 \pm 19.28(42- \\
129)\end{array}$ & $\begin{array}{c}78.07 \pm 18.93(42- \\
129)\end{array}$ & 0.452 & 0.975 \\
\hline HDL, mg/dL & $>35$ & $\begin{array}{c}36.25 \pm 8.00(23- \\
53)\end{array}$ & $\begin{array}{c}36.88 \pm 10.20(18- \\
60)\end{array}$ & $36.65 \pm 9.41(18-60)$ & -0.298 & 0.20 \\
\hline
\end{tabular}

and the mortality rate was $23 \%$. Yamano et al. (17) studied 15 biochemical indices in 91 adult patients with sepsis who were on treatment for more than two weeks in the ICU of a university hospital in Osaka, Japan. The mean ( \pm SD) age of the patients was $64( \pm 18)$ years, with a mortality rate of $41.8 \%$. In another study, Lee et al. (22) evaluated the lipid profile of 117 adult patients with sepsis (severe sepsis [ $\mathrm{n}=$ 19]) and septic shock [n=98]) who were admitted to the ICU of a large tertiary university medical center in Seoul, South Korea. The mean age of the patients was $62.7 \pm 16.2$ years, and the in-hospital mortality rate was $44.4 \%$.

In another study, Tsai et al. (32) evaluated the relationship between lipid levels, inflammatory cytokines, and clinical outcomes in 103 cirrhotic adult patients with severe sepsis in the ICUs of two university hospitals in Taiwan. The mean age of the studied patients was $54.6 \pm 13.1$ years, and the overall in-hospital mortality for the entire groups was 64.1\%. We also found two related studies in Iran. First, Barati et al. (19) compared plasma lipid levels in 70 consecutively admitted septic $(n=29)$ and non-septic ( $n$ =41) adult patients with a mean \pm SD age of $73.6 \pm 15.7$ years in an ICU in Tehran, Iran. In their study, the mortality rates were $62.1 \%$ for septic and $29.3 \%$ for non-septic patients. Second, Abdollahi et al. (18) examined the lipid profile changes in 107 adult patients with severe sepsis and septic shock in comparison with 115 non-septic patients admitted to a medical ICU in Semnan, Iran. The mean \pm SD age was $74.2 \pm 15.2$ and $68 \pm 17.3$ years, and in-hospital fatality was $76.6 \%$ and $46.9 \%$ for septic and non-septic patients, respectively. Gharebaghi et al. (33) studied 139 patients with Gram-negative sepsis in the ICUs of two tertiary educational hospitals in Urmia, Iran, in 2015 and reported the mean age of $68.29 \pm 17.4$ years and a mortality rate of $46.8 \%$ for the patients. As can be seen, the mean age of patients with sepsis in different studies is approximately similar, but the mortality rates differ depending on the setting.
In developed countries, the in-hospital mortality rates of severe sepsis and septic shock are now closer to $15 \%$ to $35 \%$ $(2,34)$. Still, in developing countries such as Iran, the mortality rate is higher. However, the severity of the disease is also effective in mortality rates. In epidemiological studies $(2,4)$, all patients with sepsis are considered, but in our survey and other similar reports $(18,19,22,32)$, patients with sepsis, severe sepsis, or septic shock were enrolled.

Regarding the lipid profile changes, although we found lower mean values for TG, total cholesterol, and HDL in the non-survival group than in the survival group, only the difference in the mean TG levels was statistically significant $(P=0.002)$. Similarly, Lee et al. (22) reported significantly lower levels of TG and free fatty acids in non-survival patients with sepsis on the day of admission. Barati et al. (19) also reported higher initial levels of cholesterol in nonsurvival than in survival patients with sepsis $(101.6 \pm 37.5$ vs. $69.4 \pm 8.3 \mathrm{mg} / \mathrm{dL}$, respectively, $\mathrm{P}<0.001$ ) but no significant difference was found in TG levels.

In other studies, Luthold et al. (31) found that the HDL and total cholesterol levels were lower in infectious critically ill patients than in non-infectious critically ill patients. Also, they concluded that the diagnostic accuracy of C-reactive protein (CRP) was not better than that of HDL, but the diagnostic accuracy of procalcitonin was superior to that of HDL. Abdollahi et al. (18) also reported considerably lower cholesterol levels on the first day after admission in septic than in non-septic patients. They also found a statistically significant reverse relationship between the HDL level and mortality in septic patients. Yamano et al. (17) concluded that only low total cholesterol and high total bilirubin were associated with the prognosis of severely septic patients.

Chien et al. (35) assessed the initial serum levels of lipids and lipoproteins and their correlations with the clinical outcome of 63 patients with severe sepsis in a medical 
ICU of a tertiary university hospital in Taiwan. They concluded that a low HDL cholesterol level on the first day of severe sepsis was significantly associated with increased mortality and adverse clinical outcomes. In another descriptive cross-sectional study, Moini et al. (23) measured the serum lipid levels (total cholesterol, LDL, and HDL) and APACHE IV score on the first and second days after ICU admission in 100 patients. They reported significant relationships between the real mortality rate and the cholesterol level of the first and second days, the LDL levels of the first and second days, and the HDL levels of the first day. A retrospective analysis of 568 septic patients and 475 non-septic patients in a university hospital in Beijing, China, revealed that the plasma cholesterol levels in patients with sepsis were significantly lower, and the levels were significantly lower in the death group than in the survival group. The authors concluded that total cholesterol might be used as a clinical indicator to assess the outcome of patients with sepsis (36).

In terms of mechanism, in normal conditions, LDL particles transport cholesterol, phospholipids, and lipidsoluble vitamins from the liver to extra-hepatic tissues while HDL particles play a significant role in the reverse transport of cholesterol from peripheral tissues (including foam cells in the arterial wall) to the liver (37). However, plasma lipids can be affected by acute illnesses (38). The exact pathophysiological mechanisms underlying the changes in plasma lipid levels in severe illnesses and sepsis have never been fully understood (39). Lipoprotein is capable of binding to endotoxins (29). A high level of endotoxin lipopolysaccharide, as occurs in severe sepsis, depresses the activity of lipoprotein lipase and impedes triglyceride disposal, resulting in marked elevations of plasma triglycerides (23). A study claimed that acute conditions (e.g., sepsis or septic shock) induce no decrease but an increase in triglyceride production in men (23). Some authors suggested a possible role for statins $(24-28,40)$ and phospholipid emulsion (41) in preventing or treating sepsis. However, the anti-inflammatory effects of statins may be independent of their lipid-lowering ability (42).

Finally, the nature of the changes in the lipid profile is controversial in acute infections (19), and there are many inconsistencies among different studies. A recent study of the epidemiology and costs of sepsis in the United States reported that among 2,566,689 hospitalized patients with sepsis between 2010 and 2016, 33.1\% had hyperlipidemia (2). Whether the observed changes in the lipid profile of patients with sepsis, particularly between survival and nonsurvival groups, are significant or not deserves further investigation, especially in the form of systematic reviews and meta-analyses.

This study had some limitations that have to be pointed out. Serum lipid levels were measured once, and the trend of lipid profile changes was not clear. Another limitation of the current study was the absence of a nonseptic control group. It would be better if we used a scoring system to assess the condition of patients at the time of ICU admission.

\subsection{Conclusions}

Our study illustrated that the low level of triglyceride is a poor prognostic factor for the mortality of patients with sepsis. This may be attributed to alterations in serum lipid metabolism during sepsis. However, the exact mechanisms have never been fully understood. Large-scale studies are required to confirm the role of lipids and lipoproteins in the outcomes of ICU patients with sepsis.

\section{Footnotes}

Authors' Contribution: Study concept and design: Rahim Nejadrahim and Saina Mobarhan. Analysis and interpretation of data: Mohammad Delirrad. Literature review: Mohammad Delirrad and Rahim Nejadrahim. Drafting of the manuscript: Mohammad Delirrad. Critical revision of the manuscript for important intellectual content: Rahim Nejadrahim, Mohammad Delirrad, and Naser Gharebaghi. Review of the final version of the manuscript before submission: All authors. The first revision of the manuscript: Mohammad Delirrad, Rahim Nejadrahim, and Naser Gharebaghi. Major Revision of the submitted manuscript: Mohammad Delirrad and Rahim Nejadrahim.

Conflict of Interests: The authors have no known conflicts of interest associated with the investigation, writing, and publication of this document.

Ethical Approval: The study was conducted following the Helsinki Declaration, and it was approved by the Ethics Committee of the Deputy of Research and Technology, Urmia University of Medical Sciences, Urmia, Iran (no.: 9501 32 27505).

Funding/Support: This study was supported by a grant from the Urmia University of Medical Sciences (no.: 9501 32 27505).

Informed Consent: Written informed consent was obtained from patients (or their relatives) in hospital documents for performing this research project, data analysis, and publication of the final results without revealing patients' identities.

\section{References}

1. Gotts JE, Matthay MA. Sepsis: pathophysiology and clinical management. Bmj. 2016;353. i1585. doi: 10.1136/bmj.i1585. [PubMed: 27217054]. 
2. Paoli CJ, Reynolds MA, Sinha M, Gitlin M, Crouser E. Epidemiology and Costs of Sepsis in the United States-An Analysis Based on Timing of Diagnosis and Severity Level. Crit Care Med. 2018;46(12):1889-97. doi: 10.1097/ccm.0000000000003342. [PubMed: 30048332]. [PubMed Central: PMC6250243]

3. Huang C, Ruan S, Tsai Y, Ku S, Yu C. Clinical Trajectories and Causes of Death in Septic Patients with a Low APACHE II Score. Journal of clinical medicine. 2019;8(7):1064. doi: 10.3390/jcm8071064. [PubMed: 31330785].

4. Mayr FB, Yende S, Angus DC. Epidemiology of severe sepsis. Virulence. 2014;5(1):4-11. doi: 10.4161/viru.27372. [PubMed: 24335434].

5. Elke G, Bloos F, Wilson DC, Meybohm P. Identification of developing multiple organ failure in sepsis patients with low or moderate SOFA scores. Crit Care. 2018;22(1):147. doi: 10.1186/s13054-018-2084-z. [PubMed: 29871660]. [PubMed Central: PMC5989334].

6. Innocenti F, Tozzi C, Donnini C, De Villa E, Conti A, Zanobetti M, et al. SOFA score in septic patients: incremental prognostic value over age, comorbidities, and parameters of sepsis severity. Intern Emerg Med. 2018;13(3):405-12. doi: 10.1007/s11739-017-1629-5. [PubMed: 28188577].

7. Khwannimit B, Bhurayanontachai R, Vattanavanit V. Comparison of the performance of SOFA, qSOFA and SIRS for predicting mortality and organ failure among sepsis patients admitted to the intensive care unit in a middle-income country. J Crit Care. 2018;44:156-60. doi: 10.1016/j.jcrc.2017.10.023. [PubMed: 29127841].

8. Spoto S, Cella E, de Cesaris M, Locorriere L, Mazzaroppi S, Nobile E, et al. Procalcitonin and MR-Proadrenomedullin Combination with SOFA and qSOFA Scores for Sepsis Diagnosis and Prognosis: A Diagnostic Algorithm. Shock. 2018;50(1):44-52. doi: 10.1097/shk.0000000000001023. [PubMed: 29023361].

9. Serafim R, Gomes JA, Salluh J, Povoa P. A Comparison of the Quick-SOFA and Systemic Inflammatory Response Syndrome Criteria for the Diagnosis of Sepsis and Prediction of Mortality: A Systematic Review and Meta-Analysis. Chest. 2018;153(3):646-55. doi: 10.1016/j.chest.2017.12.015. [PubMed: 29289687].

10. Huda AQ, Karim MR, Mahmud MA, Islam MS, Haque MF, Islam MR, et al. Use of Acute Physiology and Chronic Health Evaluation (APACHE)II and Red Cell Distribution Width (RDW) for Assessment of Mortality of Patients with Sepsis in ICU. Mymensingh Med J. 2017;26(3):585-91. [PubMed: 28919614].

11. Zhang Z, Chen K, Chen L. APACHE III Outcome Prediction in Patients Admitted to the Intensive Care Unit with Sepsis Associated Acute Lung Injury. PLoS One. 2015;10(9). e0139374. doi: 10.1371/journal.pone.0139374. [PubMed: 26422633]. [PubMed Central: PMC4589281].

12. Dabhi AS, Khedekar SS, Mehalingam V.A Prospective Study of Comparison of APACHE-IV \& SAPS-II Scoring Systems and Calculation of Standardised Mortality Rate in Severe Sepsis and Septic Shock Patients. J Clin Diagn Res. 2014;8(10):Mc09-13. doi: 10.7860/jcdr/2014/9925.5052. [PubMed: 25478384]. [PubMed Central: PMC4253202].

13. Lekkou A, Mouzaki A, Siagris D, Ravani I, Gogos CA. Serum lipid profile, cytokine production, and clinical outcome in patients with severe sepsis. J Crit Care. 2014;29(5):723-7. doi: 10.1016/j.jcrc.2014.04.018. [PubMed: 24891152].

14. Wang S, Chen D. [The correlation between procalcitonin, C-reactive protein and severity scores in patients with sepsis and their value in assessment of prognosis]. Zhonghua Wei Zhong Bing Ji Jiu Yi Хue. 2015;27(2):97-101. doi: 10.3760/cma.j.issn.2095-4352.2015.02.004. [PubMed: 25665606].

15. Li Y, Jin ZC, Cai Y, Ji MS, Liu J. Value of serum procalcitonin in evaluating the prognosis of sepsis in elderly patients with colorectal cancer undergoing emergency colorectal surgery. Indian J Surg. 2013;75(2):86-93. doi: 10.1007/s12262-012-0631-4. [PubMed: 24426400]. [PubMed Central: PMC3644167].

16. Moretti D, Ramirez MM, Settecase CJ, Bagilet DH, Quaglino MB. [Usefulness of procalcitonin upon admission to intensive care in the diagnosis and prognosis of sepsis]. Med Intensiva. 2013;37(3):156-62. doi: 10.1016/j.medin.2012.03.018. [PubMed: 22658964].

17. Yamano S, Shimizu K, Ogura H, Hirose T, Hamasaki T, Shimazu T, et al. Low total cholesterol and high total bilirubin are associated with prognosis in patients with prolonged sepsis. J Crit Care. 2016;31(1):3640. doi: 10.1016/j.jcrc.2015.09.033. [PubMed: 26596698].

18. Abdollahi O, Gohari. Ali, Nobakhtrad M, Golshahi H. Comparison of lipid profile changes in patients with severe sepsis and septic shock versus nonseptic patients admitted to the medical ICU of Semnan Kosar Hospital and its association with hospital mortality from 2013 to 2014. Scientific-Research Journal of Shahed University. 2016;120.

19. Barati M, Nazari MR, Talebi-Taher M, Farhadi N. Comparison of Lipid Profile in Septic and Non-Septic Patients. Iran J Clin Infect Dis. 2011;6(4):144-7.

20. Bermudes ACG, de Carvalho WB, Zamberlan P, Muramoto G, Maranhao RC, Delgado AF. Changes in lipid metabolism in pediatric patients with severe sepsis and septic shock. Nutrition. 2018;47:104-9. doi: 10.1016/j.nut.2017.09.015. [PubMed: 29429528].

21. Feng Q, Wei WQ, Chaugai S, Leon BGC, Mosley JD, Leon DAC, et al. Association Between Low-Density Lipoprotein Cholesterol Levels and Risk for Sepsis Among Patients Admitted to the Hospital With Infection. JAMA Netw Open. 2019;2(1). e187223. doi: 10.1001/jamanetworkopen.2018.7223. [PubMed: 30657536]

22. Lee SH, Park MS, Park BH, Jung WJ, Lee IS, Kim SY, et al. Prognostic Implications of Serum Lipid Metabolism over Time during Sepsis. Biomed Res Int. 2015;2015:789298. doi: 10.1155/2015/789298. [PubMed: 26351639]. [PubMed Central: PMC4553311].

23. Moini L, Mozafari A, Peyroshabani B. Evaluation of the Relationship between Serum Lipid Level (Total Cholesterol, LDL, HDL) and APACHE IV Score in ICU Patients. HBI_Journals. 2014;17(2):64-72.

24. Bedi P, Chalmers JD, Graham C, Clarke A, Donaldson S, Doherty C, et al. A Randomized Controlled Trial of Atorvastatin in Patients With Bronchiectasis Infected With Pseudomonas Aeruginosa: A Proof of Concept Study. Chest. 2017;152(2):368-78. doi: 10.1016/j.chest.2017.05.017. [PubMed: 28554732].

25. Goodin J, Manrique C, Dulohery M, Sampson J, Saettele M, Dabbagh O. Effect of statins on the clinical outcomes of patients with sepsis. Anaesth Intensive Care. 2011;39(6):1051-5. [PubMed: 22165357].

26. Kruger P, Bailey M, Bellomo R, Cooper DJ, Harward M, Higgins A, et al. A multicenter randomized trial of atorvastatin therapy in intensive care patients with severe sepsis. Am J Respir Crit Care Med. 2013;187(7):743-50. doi: 10.1164/rccm.201209-1718OC. [PubMed: 23348980].

27. Ou SY, Chu H, Chao PW, Ou SM, Lee YJ, Kuo SC, et al. Effect of the use of low and high potency statins and sepsis outcomes. Intensive Care Med. 2014;40(10):1509-17. doi: 10.1007/s00134-014-3418-1. [PubMed: 25091791].

28. Pasin L, Landoni G, Castro ML, Cabrini L, Belletti A, Feltracco P, et al. The Effect of Statins on Mortality in Septic Patients: A Meta-Analysis of Randomized Controlled Trials. PLOS ONE. 2014;8(12). e82775. doi: 10.1371/journal.pone.0082775.

29. Esteban E, Ferrer R, Alsina L, Artigas A. Immunomodulation in sepsis: the role of endotoxin removal by polymyxin B-immobilized cartridge. Mediators of inflammation. 2013;2013:507539. doi: 10.1155/2013/507539. [PubMed: 24249974].

30. Singer M, Deutschman CS, Seymour CW, Shankar-Hari M, Annane $\mathrm{D}$, Bauer $\mathrm{M}$, et al. The Third International Consensus Definitions for Sepsis and Septic Shock (Sepsis-3). JAMA. 2016;315(8):801-10. doi: 10.1001/jama.2016.0287. [PubMed: 26903338].

31. Luthold S, Berneis K, Bady P, Muller B. Effects of infectious disease on plasma lipids and their diagnostic significance in critical illness. Eur J Clin Invest. 2007;37(7):573-9. doi: 10.1111/j.1365-2362.2007.01826.x. [PubMed: 17576209].

32. Tsai MH, Peng YS, Chen YC, Lien JM, Tian YC, Fang JT, et al. Low serum concentration of apolipoprotein A-I is an indicator of poor prognosis in cirrhotic patients with severe sepsis. J Hepatol. 2009;50(5):906-15. 
doi: 10.1016/j.jhep.2008.12.024. [PubMed: 19304335].

33. Gharebaghi N, Valizade-Hasanloei MA, Mehdizadeh-khalifani A, Pakzad S, Lahooti D. Neutrophil-to-lymphocyte ratio in patients with gram-negative sepsis admitted to intensive care unit. Anaesthesiology Intensive Therapy. 2019;51(5):11-6. doi: 10.5603/AIT.a2019.0009.

34. Angus DC, van der Poll T. Severe sepsis and septic shock. N Engl J Med. 2013;369(21):2063. doi: 10.1056/NEJMc1312359. [PubMed: 24256390].

35. Chien JY, Jerng JS, Yu CJ, Yang PC. Low serum level of high-density lipoprotein cholesterol is a poor prognostic factor for severe sepsis. Crit Care Med.2005;33(8):1688-93. [PubMed: 16096442].

36. Bai J, Lin J, Zhuang H, Guo D, Yang X, Duan M. [Changes in plasma cholesterol level and risk factors of death in patients with sepsis]. Zhonghua Wei Zhong Bing Ji Jiu Yi Xue. 2016;28(2):164-8. Chinese. doi: 10.3760/cma.j.issn.2095-4352.2016.02.015. [PubMed: 26911950].

37. Tosheska Trajkovska K, Topuzovska S. High-density lipoprotein metabolism and reverse cholesterol transport: strategies for raising HDL cholesterol. Anatolian journal of cardiology. 2017;18(2):149-54. doi: 10.14744/AnatolJCardiol.2017.7608. [PubMed: 28766509].

38. Wang X, Nijman R, Camuzeaux S, Sands C, Jackson H, Kaforou M, et al. Plasma lipid profiles discriminate bacterial from viral infection in febrile children. Scientific Reports. 2019;9(1):17714. doi: 10.1038/s41598019-53721-1.

39. Tanaka S, Labreuche J, Drumez E, Harrois A, Hamada S, Vigue B, et al. Low HDL levels in sepsis versus trauma patients in intensive care unit. Ann Intensive Care. 2017;7(1):60. doi: 10.1186/s13613-017-0284-3. [PubMed: 28589535]. [PubMed Central: PMC5461227].

40. McDowell SA, Ma Y, Kusano R, Akinbi HT. Simvastatin is protective during Staphylococcus aureus pneumonia. Curr Pharm Biotechnol. 2011;12(9):1455-62. [PubMed: 21401521]. [PubMed Central: PMC4469268].

41. Chen J, Yan J, Cai GL, Xu QH, Gong SJ, Dai HW, et al. Structured lipid emulsion as nutritional therapy for the elderly patients with severe sepsis. Chin Med J (Engl). 2013;126(12):2329-32. [PubMed: 23786948].

42. Diamantis E, Kyriakos G, Quiles-Sanchez LV, Farmaki P, Troupis T. The Anti-Inflammatory Effects of Statins on Coronary Artery Disease: An Updated Review of the Literature. Current cardiology reviews. 2017;13(3):209-16. doi: 10.2174/1573403X13666170426104611. [PubMed: 28462692]. 